\title{
Fuzzy Second-Order Sliding Mode Control Design for a Two-Cell DC-DC Converter
}

\author{
Hanene Medhaffar (iD and Nabil Derbel \\ Control and Energy Management Laboratory (CEMLab), Sfax Engineering School, University of Sfax, Sfax, Tunisia \\ Correspondence should be addressed to Hanene Medhaffar; hanene.medhaffar@isgis.usf.tn
}

Received 7 February 2020; Accepted 8 May 2020; Published 29 May 2020

Guest Editor: Cuimei Jiang

Copyright (c) 2020 Hanene Medhaffar and Nabil Derbel. This is an open access article distributed under the Creative Commons Attribution License, which permits unrestricted use, distribution, and reproduction in any medium, provided the original work is properly cited.

\begin{abstract}
This paper presents a fuzzy second-order sliding mode controller for a two-cell DC-DC converter. For this aim, a second-order sliding mode controller and a type- 2 fuzzy system are combined to achieve an adequate control. For this reason, backgrounds on the type- 2 fuzzy sets and on the second-order sliding mode control applied to discrete systems have been presented briefly. A proposed control algorithm is then presented combining these two robust approaches. The asymptotic stability of the overall controlled system has been ensured using the Lyapunov theory. The efficiency and the robustness of the proposed controller have been tested by simulations.
\end{abstract}

\section{Introduction}

DC-DC converters are power electronic circuits used in a large variety of applications in electrical industry and power systems. These circuits are highly nonlinear and uncertain systems due to their switching properties, varying load, and inaccurate passive elements $[1,2]$.

Multicell converters have been widely used in real applications due to their ability to support high voltages. Indeed, structures of these converters consist of a series connection of switching devices with passive storage elements, which generate intermediate voltage levels allowing for the reduction of the voltage in all switches by dividing it between intermediate levels [3]. Moreover, multicell converters can be associated very easily due to their modular structure [4].

Nevertheless, it has been shown that multicell DC-DC converters may exhibit chaotic behavior under traditional controllers [5]. Several control techniques have been proposed for controlling chaos [6] or in chaos synchronization problems $[7,8]$. Therefore, the control method influences the dynamical behavior of the power converter. Many conventional control approaches, dealing with this subject, can be found in the literature like PID [9] or sliding mode control.

The concept of the sliding mode control has drawn the attention of researchers in the last three decades. It is noted that the sliding mode control is a powerful robust control strategy treating the model uncertainties and external disturbances. The design and the implementation of the discretetime sliding mode control have later been considered [10-12] and are still in progress because large classes of continuous systems are controlled by digital signal processors and microprocessors. The application of this control law is confronted to a serious problem: the chattering phenomenon. High-order sliding mode control has been suggested in order to cancel this phenomenon $[13,14]$. Thus, this method consists of reducing to zero, not only the sliding function but also its high-order derivatives. Oscillations generated by the discontinuous control are transferred to the higher derivatives of the sliding function in order to reduce oscillation amplitudes while system's robustness remains intact [15]. However, this control strategy requires the knowledge of a dynamic model of the system or a disturbance estimation scheme. Fuzzy logic control has been proposed in an attempt to control nonlinear systems whose parameters are inaccurate, presenting neglected dynamics as well as time-varying systems. However, fuzzy control seems to be deficient in formal analysis and robustness aspects. To overcome this disadvantage, great efforts have been done in the integration of the combination of fuzzy techniques and sliding mode control to improve system control performances $[16,17]$. In recent 
years, there has been an increasing interest in the type- 2 fuzzy-based control [18-20] since type-2 fuzzy systems have better effects on performances of the controlled system than type-1 fuzzy systems where it is difficult to determine parameters associated with the rule base and membership functions [21-23]. Moreover, type-2 fuzzy systems give more degrees of freedom for a better representation of uncertainties compared to type-1 fuzzy sets [24].

The main objective of this work is to design a discrete-time second-order sliding mode control strategy enhanced by a stable adaptive type- 2 fuzzy inference system to cope with modeling inaccuracies and external disturbances that can arise. Numerical simulations are performed on the two-cell converter for the illustration and the verification of the proposed controller.

\section{Two-Cell DC-DC Converter}

The two-cell DC-DC converter is presented in Figure 1 where the binary command signals $U_{1}$ and $U_{2}$ are the outputs of a digital pulse width modulator (DPWM). The aim of this control is to achieve a constant voltage $V_{c}=$ $(E / 2)$ and a constant output current $i_{L}=i_{R}=I_{r}$. The twocell DC-DC converter is based on a buck chopper altered to allow higher input supply $E$ using two switching cells separated by a flying capacitor $C$ [25].

The control signals are the evolution of the duty cycles $d_{1}$ and $d_{2}$ which correspond to two switches $S_{1}$ and $S_{2}$.

It should be noted that if the floating capacitor voltage $V_{c}$ is equal to half of the input voltage, the total stress is shared equally between both switches that make this structure suitable for high-voltage applications [26].

As we have two switches $S_{1}$ and $S_{2}$, we can easily define four different operating topologies (see Table 1).

Clearly, a linear system is obtained for each topology. Consequently, a closed-form solution can be obtained for each topology to which a solution of the state space is [5]

$$
\left[\begin{array}{c}
\frac{\mathrm{d} i_{L}}{\mathrm{~d} t} \\
\frac{\mathrm{d} V_{c}}{\mathrm{~d} t}
\end{array}\right]=\left[\begin{array}{cc}
-\frac{R}{L} & \left(d_{1}-d_{2}\right) \frac{1}{L} \\
\left(d_{2}-d_{1}\right) \frac{1}{C} & 0
\end{array}\right]\left[\begin{array}{c}
i_{L} \\
V_{c}
\end{array}\right]+\left[\begin{array}{c}
\frac{E}{L}\left(1-d_{1}\right) \\
0
\end{array}\right] .
$$

The control variables are the duty cycles of the switches $S_{i}, i=1,2$. This system can be discretized using the Euler approximation as

$$
\left[\begin{array}{c}
i_{L}(k+1) \\
V_{c}(k+1)
\end{array}\right]=\left[\begin{array}{cc}
1-\frac{R T}{L} & \left(d_{1}(k)-d_{2}(k)\right) \frac{T}{L} \\
\left(d_{2}(k)-d_{1}(k)\right) \frac{T}{C} & 1
\end{array}\right]\left[\begin{array}{c}
i_{L}(k) \\
V_{c}(k)
\end{array}\right]+\left[\begin{array}{c}
\frac{E T}{L}\left(1-d_{1}(k)\right) \\
0
\end{array}\right]
$$

For the sake of reducing the number of parameters of the system, the following dimensionless and simplified model can be considered [27]:

$$
\left[\begin{array}{c}
i_{L}^{\prime}(k+1) \\
V_{c}^{\prime}(k+1)
\end{array}\right]=\left[\begin{array}{c}
\left(1-\delta_{L}\right) i_{L}^{\prime}(k)+\delta_{L} \\
V_{c}^{\prime}(k)
\end{array}\right]+\left[\begin{array}{cc}
\delta_{L}\left(V_{c}^{\prime}(k)-1\right) & -\delta_{L} V_{c}^{\prime}(k) \\
-\delta_{c} i_{L}^{\prime}(k) & \delta_{c} i_{L}^{\prime}(k)
\end{array}\right]\left[\begin{array}{l}
d_{1}(k) \\
d_{2}(k)
\end{array}\right],
$$

where $T$ is the switching period and

$$
\begin{aligned}
i_{L}^{\prime} & =\frac{R}{E} i_{L}, \\
V_{c}^{\prime} & =\frac{V_{c}}{E} .
\end{aligned}
$$

Constants $\delta_{L}$ and $\delta_{c}$ are expressed by

$$
\begin{aligned}
& \delta_{L}=\frac{R T}{L}, \\
& \delta_{c}=\frac{T}{R C} .
\end{aligned}
$$

Let us define the following new state variables:

$$
x(k)=\left[\begin{array}{c}
x_{1}(k) \\
x_{2}(k)
\end{array}\right]=\left[\begin{array}{c}
i_{L}^{\prime}(k) \\
V_{c}^{\prime}(k)
\end{array}\right] .
$$

Therefore, we obtain the following model:

$$
\begin{aligned}
x(k+1) & =\left[\begin{array}{l}
f_{1}(x(k)) \\
f_{2}(x(k))
\end{array}\right]+\left[\begin{array}{ll}
g_{11}(k) & g_{12}(k) \\
g_{21}(k) & g_{22}(k)
\end{array}\right]\left[\begin{array}{l}
d_{1}(k) \\
d_{2}(k)
\end{array}\right] \\
& =f[x(k)]+g[x(k)] u(k),
\end{aligned}
$$

where $f(k)=f[x(k)]$ and $g(k)=g[x(k)]$ should be identified by fuzzy systems.

Moreover, the applied duty cycles are not $d_{1}(k)$ and $d_{2}(k)$ but sat $\left(d_{1}(k)\right)$ and sat $\left(d_{2}(k)\right)$ where the saturation function is given by

$$
\operatorname{sat}(x)=\frac{1}{2}(1+|x|-|x-1|)
$$




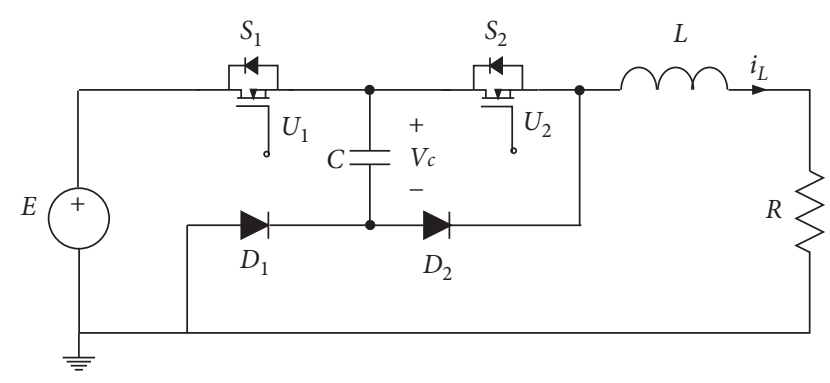

Figure 1: A two-cell DC-DC buck converter.

TABle 1: Different topologies of the two-cell DC-DC converter.

\begin{tabular}{lcc}
\hline Topologies & State of $S_{1}$ & State of $S_{2}$ \\
\hline Topology 1 & Off & On \\
Topology 2 & On & On \\
Topology 3 & On & Off \\
Topology 4 & Off & Off \\
\hline
\end{tabular}

\section{Second-Order Discrete Sliding Mode Controller}

The high-order sliding mode control concept has been introduced in the 1980s with the aim of resolving the chattering phenomenon. Indeed, the proposed strategy transfers the discontinuity on the higher derivatives of the control law. In order to obtain a discrete second-order sliding mode controller, the following second-order sliding function vector $\left(\sigma=\left[\sigma_{1}, \sigma_{2}\right]^{T}\right)$ is considered:

$$
\sigma(k+1)=s(k+1)+\beta s(k)
$$

where $\beta=\operatorname{diag}\left(\beta_{1}, \beta_{2}\right)$ with $0<\beta_{i}<1, i=1,2$ and $s(k)$ is defined by

$$
s(k)=\left[\begin{array}{l}
s_{1}(k) \\
s_{2}(k)
\end{array}\right]=\left[\begin{array}{l}
e_{1}(k)+\lambda_{1} e_{1}(k-1) \\
e_{2}(k)+\lambda_{2} e_{2}(k-1)
\end{array}\right],
$$

where $e_{1}(k)=x_{1}(k)-I_{r d}^{\prime}$ and $e_{2}(k)=x_{2}(k)-V_{c d}^{\prime} . I_{r d}^{\prime}$ and $V_{c d}^{\prime}$ are the desired output current and voltage, respectively.

$s(k)$ can be rewritten as follows:

$$
s(k)=e(k)+\lambda e(k-1),
$$

where $e(k)=\left[e_{1}(k), e_{2}(k)\right]^{T}$ and $\lambda=\operatorname{diag}\left(\lambda_{1}, \lambda_{2}\right)$.

The equivalent control should satisfy the following criteria to ensure ideal sliding motion [28]:

$$
\sigma(k+1)=\sigma(k)=0 .
$$

Thus, using equations (7), (11), and (12), the equivalent control vector can be calculated as follows:

$$
u_{\mathrm{eq}}(k)=[g(k)]^{-1}\left[x_{d}-f(k)-\lambda e(k)-\beta s(k)\right],
$$

where $x_{d}=\left[I_{r d}^{\prime}, V_{c d}^{\prime}\right]^{T}$.

The robustness is ensured by the addition of a discontinuous term (sign of the second-order sliding function vector). By analogy to the continuous-time case, the following control at the instant $k$ is then [29]

$$
u(k)=[g(k)]^{-1}\left[x_{d}-f(k)-\lambda e(k)-\beta s(k)+u_{\mathrm{dis}}(k)\right],
$$

where $u_{\text {dis }}(k)=u_{\text {dis }}(k-1)-\rho \operatorname{sign}(\sigma(k))$.

In [28], the authors propose another version of $u_{\text {dis }}(k)$ as follows:

$$
u_{\text {dis }}(k)=-\rho \operatorname{sign}[\sigma(k-1)]
$$

where $\rho=\operatorname{diag}\left(\rho_{1}, \rho_{2}\right)>0$. In the following, this switching function will be applied. To obtain the sliding mode control law, we will use fuzzy systems to approximate unknown system functions $f(k)$ and $g(k)$. Moreover, an adaptive adjusting law will be designed.

\section{Type-2 Fuzzy System}

The type- 2 fuzzy system is an extension of the type-1 fuzzy system where uncertainties are represented by the addition of extra dimensions, which provide more degrees of freedom for a greater representation of uncertainties compared to type-1. In addition, using type-2 fuzzy set to represent fuzzy inputs and outputs will result in the reduction of the fuzzy logic rule base when compared to use of type-1 fuzzy sets. Indeed, type- 2 fuzzy sets help to cover the same range as type- 1 fuzzy sets with smaller number of labels and the rule reduction will be greater when the number of the fuzzy logic inputs increases [30]. In order to approximate unknown system functions $f(k)$ and $g(k)$, the proposed type-2 fuzzy system is characterized by fuzzy IFTHEN rules. Similar to the type- 1 fuzzy system, the type- 2 fuzzy system includes a fuzzifier, a rule base, a fuzzy inference engine, and an output processor. In the type-2 fuzzy system, the output processor includes a type-reducer and a defuzzifier [31].

While designing type-2 fuzzy systems for the estimation of unknown system functions, type-2 Gaussian membership functions with uncertain standard deviations are used in the fuzzification process of inputs $x_{1}(k)$ and $x_{2}(k)$. This choice is motivated by the fact that they are easier to represent and optimize, are always continuous, and are faster to compute for small rule basis [24]. Mathematical expressions for membership functions are expressed as

$$
\mu\left(x_{i}(k)\right)=\exp \left(-\frac{\left(x_{i}(k)-m_{i}\right)^{2}}{2 \sigma_{i}^{2}}\right), \quad i=1,2,
$$

where $m_{i}$ and $\sigma_{i}$ are centers and widths of membership functions.

In general, both $m_{i}$ and $\sigma_{i}$ may be uncertain in the intervals $\left[m_{1 i}, m_{2 i}\right]$ and $\left[\sigma_{1 i}, \sigma_{2 i}\right]$, respectively. The present work assumes that centers do not have any uncertainty and it considers only membership functions with uncertain standard deviation.

Each input variable $\left(x_{1}(k)\right.$ or $\left.x_{2}(k)\right)$ is quantified into fuzzy sets. In this paper, the singleton fuzzification strategy is considered.

The adopted form for rules is the zero-order Sugeno model where parameters of consequent parts are taken as singletons and they will be tuned, later, by adaptive laws. 
The knowledge base for the fuzzy logic system comprises a collection of fuzzy IF-THEN rules of the form:

$R_{(j)}$ : If $\left[\left(x_{1}(k)\right.\right.$ is $\left.A_{1 j}\right)$ and $\left(x_{2}(k)\right.$ is $\left.\left.A_{2 j}\right)\right]$ then $\left[\left(y(x(k))=b_{j}\right)\right]$,

where $j=1, \ldots, H . H$ is the rule number of the fuzzy logic system.

The inference engine combines fired rules and gives a mapping from input type-2 fuzzy sets to output fuzzy sets. Each membership function of the antecedent part is represented by a lower and an upper membership function $\underline{\mu}_{A_{i j}}\left(x_{i}(k)\right)$ and $\bar{\mu}_{A_{i j}}\left(x_{i}(k)\right)[22]$ :

$$
\mu_{A_{i j}}\left(x_{i}(k)\right)=\left[\underline{\mu}_{A_{i j}}\left(x_{i}(k)\right), \bar{\mu}_{A_{i j}}\left(x_{i}(k)\right)\right] \text {. }
$$

The firing strengths can be calculated adopting the product inference as

$$
\begin{aligned}
& \underline{h}_{j}=\underline{\mu}_{A_{1 j}}\left(x_{1}(k)\right) \times \underline{\mu}_{A_{2 j}}\left(x_{2}(k)\right), \\
& \bar{h}_{j}=\bar{\mu}_{A_{1 j}}\left(x_{1}(k)\right) \times \bar{\mu}_{A_{2 j}}\left(x_{2}(k)\right) .
\end{aligned}
$$

For computing the output of the fuzzy system, we use the type-reduction approach and then defuzzification operations. The type-reduction approach combines the firing interval of rules and the corresponding rule consequents. There are several methods for it's design and the most commonly used is the center-of-sets type-reducer [32].

In our design, we bypass the type reduction and compute the defuzzified output directly by adopting the method of Nie and Tan [33].

Thus, the output of the fuzzy system is computed as

$$
y(x(k))=\frac{\sum_{j=1}^{H} b_{j}\left(\underline{h}_{j}+\bar{h}_{j}\right)}{\sum_{j=1}^{H}\left(\underline{h}_{j}+\bar{h}_{j}\right)} .
$$

By introducing the concept of fuzzy basis function vector $\xi$, equation (20) can be rewritten as

$$
y(x(k))=\theta^{T} \xi(k)
$$

where $\theta=\left[b_{1}, \ldots, b_{H}\right]^{T}, \xi(k)=\left[\xi_{1}(k), \ldots, \xi_{H}(k)\right]$, and

$$
\xi_{j}(k)=\frac{\left(\underline{h}_{j}+\bar{h}_{j}\right)}{\sum_{i=1}^{H}\left(\underline{h}_{i}+\bar{h}_{i}\right)} .
$$

\section{Fuzzy Second-Order Sliding Mode Control}

In order to derive the sliding mode control, fuzzy functions $\hat{f}_{i}\left(x(k) / \theta_{f_{i}}\right)$ and $\hat{g}_{i j}\left(x(k) / \theta_{g_{i j}}\right)$ are used to approximate $f_{i}(x(k))$ and $g_{i j}(x(k))$, respectively, where $i, j=1,2$. They are expressed by

$$
\begin{aligned}
\widehat{f}_{i}\left(x(k) / \theta_{f_{i}}\right) & =\theta_{f_{i}}^{T} \xi_{f_{i}}(x(k)), \\
\widehat{g}_{i j}\left(x(k) / \theta_{g_{i j}}\right) & =\theta_{g_{i j}}^{T} \xi_{g_{i j}}(x(k)),
\end{aligned}
$$

where $\xi_{f_{i}}(x(k))$ and $\xi_{g_{i j}}(x(k))$ are vectors of fuzzy basis which are supposed to be fixed, while parameters $\theta_{f_{i}}$ and $\theta_{g_{i j}}$ are variables which will be designed by adaptive laws.

Then, we can select the control law as

$$
\begin{aligned}
u(k)= & {\left[\hat{g}\left(x(k) / \theta_{g}\right)\right]^{-1}\left[x_{d}-\hat{f}\left(x(k) / \theta_{f}\right)-\lambda e(k)\right.} \\
& \left.-\beta s(k)+u_{\text {dis }}(k)\right] .
\end{aligned}
$$

Let $\theta_{f_{i}}^{*}$ and $\theta_{g_{i j}}^{*}$ be optimal parameter vectors of fuzzy logic systems. Minimum approximation errors can be defined as follows:

$$
\begin{aligned}
& w_{f_{i}}(k)=f_{i}(x(k))-\widehat{f}_{i}\left(x(k) / \theta_{f_{i}}^{*}\right), \\
& w_{g_{i j}}(k)=g_{i j}(x(k))-\widehat{g}_{i j}\left(x(k) / \theta_{g_{i j}}^{*}\right) .
\end{aligned}
$$

Therefore, $\sigma(k)$ can be rewritten as

$$
\begin{aligned}
\sigma(k) & =s(k+1)+\beta s(k) \\
& =e(k+1)+\lambda e(k)+\beta s(k) \\
& =x(k+1)-x_{d}+\lambda e(k)+\beta s(k) \\
& =f(k)+g(k) u(k)-\hat{g}\left(x(k) / \theta_{g}\right) u(k)-\widehat{f}\left(x(k) / \theta_{f}\right)-\lambda e(k)-\beta s(k)+u_{\mathrm{dis}}(k)+\lambda e(k)+\beta s(k) \\
& =f(k)-\hat{f}\left(x(k) / \theta_{f}\right)+\left(g(k)-\hat{g}\left(x(k) / \theta_{g}\right)\right) u(k)+u_{\mathrm{dis}}(k) \\
& =\hat{f}\left(x(k) / \theta_{f}^{*}\right)-\hat{f}\left(x(k) / \theta_{f}\right)+w_{f}(k)+\left(\hat{g}\left(x(k) / \theta_{g}^{*}\right)-\hat{g}\left(x(k) / \theta_{g}\right)+w_{g}(k)\right) u(k)+u_{\mathrm{dis}}(k) .
\end{aligned}
$$


Then, $\sigma_{i}(k)$ can be expressed by

$$
\begin{aligned}
\sigma_{i}(k)= & \hat{f}_{i}\left(x(k) / \theta_{f_{i}}^{*}\right)-\hat{f}_{i}\left(x(k) / \theta_{f_{i}}\right)+w_{f_{i}}(k) \\
& +\sum_{j=1}^{2}\left[\widehat{g}_{i j}\left(x(k) / \theta_{g_{i j}}^{*}\right)-\widehat{g}_{i j}\left(x(k) / \theta_{g_{i j}}\right)+w_{g_{i j}}(k)\right] u_{j}(k)+u_{i, \text { dis }}(k) \\
= & \Phi_{f_{i}}^{T}(k) \xi_{f_{i}}(x(k))+w_{f_{i}}(k)+\sum_{j=1}^{2}\left[\Phi_{g_{i j}}^{T}(k) \xi_{g_{i j}}(x(k))+w_{g_{i j}}(k)\right] u_{j}(k)+u_{i, \text { dis }}(k) \\
= & \Phi_{f_{i}}^{T}(k) \xi_{f_{i}}(x(k))+\sum_{j=1}^{2}\left[\Phi_{g_{i j}}^{T}(k) \xi_{g_{i j}}(x(k))\right] u_{j}(k)+W_{i}(k)+u_{i, \text { dis }}(k),
\end{aligned}
$$

where $\Phi_{f_{i}}(k)$ and $\Phi_{g_{i j}}$ represent the fuzzy parameter errors such that

$$
\begin{gathered}
\Phi_{f_{i}}(k)=\theta_{f_{i}}^{*}-\theta_{f_{i}}(k), \\
\Phi_{g_{i j}}(k)=\theta_{g_{i j}}^{*}-\theta_{g_{i j}}(k) .
\end{gathered}
$$

$W_{i}(k)$ is the minimum approximation error that can be defined as follows:

$$
W_{i}(k)=w_{f_{i}}(k)+\sum_{j=1}^{2} w_{g_{i j}}(k) u_{j}(k) .
$$

Theorem 1. The following adaptive laws for adjusting parameter vectors $\theta_{f}$ and $\theta_{g}$ :

$$
\begin{aligned}
& \Delta \theta_{f_{i}}(k+1)=\rho_{f} \sigma_{i}(k) \xi_{f_{i}}(x(k+1)), \\
& \Delta \theta_{g_{i j}}(k+1)=\rho_{g} \sigma_{i}(k) \xi_{g_{i j}}(x(k+1)) u_{j}(k+1),
\end{aligned}
$$

asymptotically stabilize system (7) controlled by (24), where $\rho_{f}$ and $\rho_{g}$ are positive constants which determine the rate of adaptation.

Proof. The Lyapunov function candidate is chosen as

$$
V(k)=\sum_{i=1}^{2} V_{i}(k)
$$

where

$$
\begin{aligned}
V_{i}(k)= & \frac{1}{2} \sigma_{i}^{2}(k)+\frac{1}{2 \rho_{f}}\left(\Phi_{f_{i}}(k+1)^{T} \Phi_{f_{i}}(k+1)\right) \\
& +\frac{1}{2 \rho_{g}} \sum_{j=1}^{2}\left(\Phi_{g_{i j}}(k+1)^{T} \Phi_{g_{i j}}(k+1)\right) .
\end{aligned}
$$

Then, $\Delta V_{i}(k)=V_{i}(k+1)-V_{i}(k)$ can be calculated using a Taylor series expansion:

$$
\begin{aligned}
V_{i}(k+1)= & V_{i}(k)+\frac{\partial V_{i}(k)}{\partial \sigma_{i}(k)} \Delta \sigma_{i}(k)+\frac{\partial V_{i}(k)}{\partial \Phi_{f_{i}}(k+1)} \Delta \Phi_{f_{i}}(k+1) \\
& +\frac{\partial V_{i}(k)}{\partial \Phi_{g_{i j}}(k+1)} \Delta \Phi_{g_{i j}}(k+1)+\underbrace{O\left(\Delta \sigma_{i}(k), \Delta \Phi_{f_{i}}(k+1), \Delta \Phi_{g_{i j}}(k+1)\right)^{2}}_{O_{k}} .
\end{aligned}
$$

$\Delta V_{i}(k)$ can be obtained by substituting the values of the partial derivatives into equation (34):

$$
\Delta V_{i}(k)=\sigma_{i}(k) \Delta \sigma_{i}(k)+\frac{1}{\rho_{f}} \Phi_{f_{i}}(k+1)^{T} \Delta \Phi_{f_{i}}(k+1)+\frac{1}{\rho_{g}} \sum_{j=1}^{2} \Phi_{g_{i j}}(k+1)^{T} \Delta \Phi_{g_{i j}}(k+1)+O_{k} .
$$


Equation (35) can be simplified after substituting $\Delta \sigma_{i}(k) \equiv \sigma_{i}(k+1)-\sigma_{i}(k)$ and equation (27) at $k+1$ time steps:

$$
\begin{aligned}
\Delta V_{i}(k)= & \sigma_{i}(k)\left[\sigma_{i}(k+1)-\sigma_{i}(k)\right]+\frac{1}{\rho_{f}} \Phi_{f_{i}}(k+1)^{T} \Delta \Phi_{f_{i}}(k+1) \\
& +\frac{1}{\rho_{g}} \sum_{j=1}^{2} \Phi_{g_{i j}}(k+1)^{T} \Delta \Phi_{g_{i j}}(k+1)+O_{k} \\
= & \sigma_{i}(k)\left[\Phi_{f_{i}}^{T}(k+1) \xi_{f_{i}}(x(k+1))+\sum_{j=1}^{2}\left(\Phi_{g_{i j}}^{T}(k+1) \xi_{g_{i j}}(x(k+1))\right) u_{j}(k+1)+W_{i}(k+1)+u_{i, \text { dis }}(k+1)\right] \\
& -\sigma_{i}^{2}(k)+\frac{1}{\rho_{f}} \Phi_{f_{i}}(k+1)^{T} \Delta \Phi_{f_{i}}(k+1)+\frac{1}{\rho_{g}} \sum_{j=1}^{2} \Phi_{g_{i j}}(k+1)^{T} \Delta \Phi_{g_{i j}}(k+1)+O_{k} \\
= & -\sigma_{i}^{2}(k)+\frac{1}{\rho_{f}} \Phi_{f_{i}}(k+1)^{T} \underbrace{\left[\rho_{f} \xi_{f_{i}}(x(k+1)) \sigma_{i}(k)+\Delta \Phi_{f_{i}}(k+1)\right]}_{=0}+\sigma_{i}(k) W_{i}(k+1) \\
& +\sigma_{i}(k) u_{i, \mathrm{dis}}(k+1)+\frac{1}{\rho_{g}} \sum_{j=1}^{2} \Phi_{g_{i j}}(k+1)^{T} \underbrace{\left.\rho_{g} \xi_{g_{i j}}(x(k+1)) \sigma_{i}(k) u_{j}(k+1)+\Delta \Phi_{g_{i j}}(k+1)\right]+O_{k}}_{=0} \\
= & -\sigma_{i}^{2}(k)+\sigma_{i}(k) W_{i}(k+1)-\rho_{i} \mid \sigma_{i}(k)+O_{k},
\end{aligned}
$$

where

$$
\begin{gathered}
\Delta \Phi_{f_{i}}(k+1)=-\Delta \theta_{f_{i}}(k+1), \\
\Delta \Phi_{g_{i j}}(k+1)=-\Delta \theta_{g_{i j}}(k+1) .
\end{gathered}
$$

It is obvious that the term $W_{i}(k+1)$ should be very small in the adaptive fuzzy system [34], verifying

$$
\left|W_{i}(k+1)\right| \leq \varepsilon_{i} \ll \rho_{i},
$$

where $\varepsilon_{i}$ is a positive small parameter.

Then, adaptive laws (30) and (31) yield

$$
\begin{aligned}
\Delta V_{i}(k) & \leq-\sigma_{i}^{2}(k)+\varepsilon_{i}\left|\sigma_{i}(k)\right|-\rho_{i}\left|\sigma_{i}(k)\right|+O_{k} \\
& \leq-\sigma_{i}^{2}(k)-\left(\rho_{i}-\varepsilon_{i}\right)\left|\sigma_{i}(k)\right|+O_{k} \leq 0
\end{aligned}
$$

Consequently, $\Delta V(k) \leq 0$ which guarantees the stability of the system.

\section{Simulation Results}

In order to illustrate and validate the proposed control scheme, numerical simulation was carried out. The parameter values used for the power stage circuit are as follows: $R=25 \Omega, L=10 \mathrm{mH}, C=16 \mu \mathrm{F}, E=90 \mathrm{~V}$, and $f_{s}=25 \mathrm{kHz}$. The aim is to achieve a constant voltage $V_{c d}^{\prime}=0.5$ and a constant output current $I_{r d}^{\prime}=0.6$. To approximate unknown system functions $f(k)$ and $g(k), x_{1}(k)$ or $x_{2}(k)$ is quantified into five fuzzy sets: NL-negative large, NS-negative small, ZO_zero, PS-positive small, and PL-positive large, as shown in Figure 2.

In Figure 3, we represent the time evolution of the current and the voltage in the two-cell DC-DC converter. We can notice that the voltage requires about 7 switching periods to drive the two-cell converter to the desired value $V_{c d}$.

Figure 4 illustrates the evolution of the duty cycles $d_{1}(k)$ and $d_{2}(k)$ which converge promptly to a constant value.

It is obvious that the control objective is achieved: the proposed control scheme offers a fast tracking and a smooth control action. Moreover, this result is obtained without using the details of the plant dynamics in the development of the control law.

In order to illustrate the robustness of the proposed controller, we have considered a variation of the resistance $R$ which becomes 1.25 times its initial value after 20 periods. Figure 5 presents the evolution of the current and the voltage after applying this perturbation. It is obvious that this disturbance is rejected effectively by the controller, and the state variables reach their desired values, rapidly.

Figure 6 illustrates a comparison between a proposed control and a PI controller proposed in [5]. The PI controller is given by 


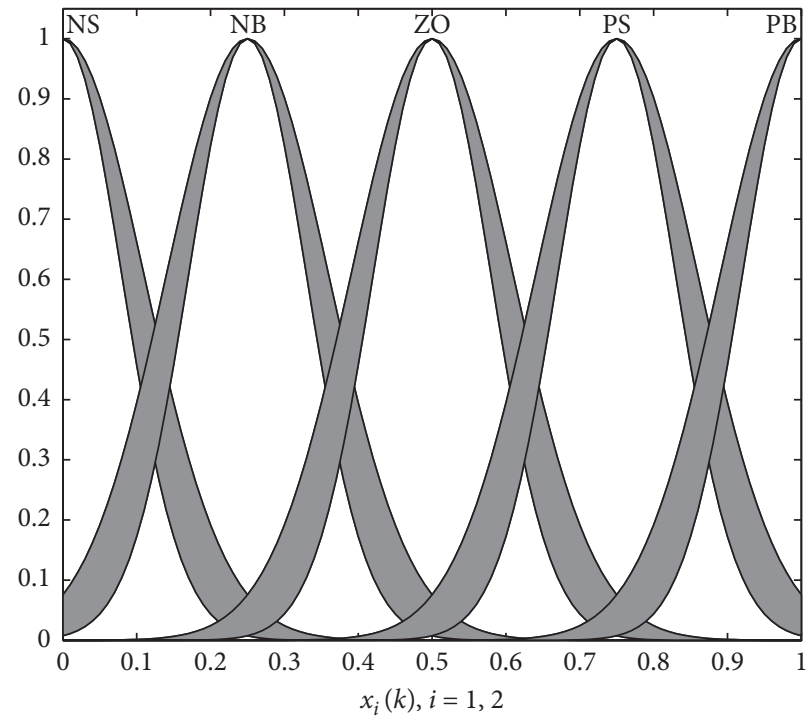

Figure 2: $x_{1}(k)$ and $x_{2}(k)$ membership functions.

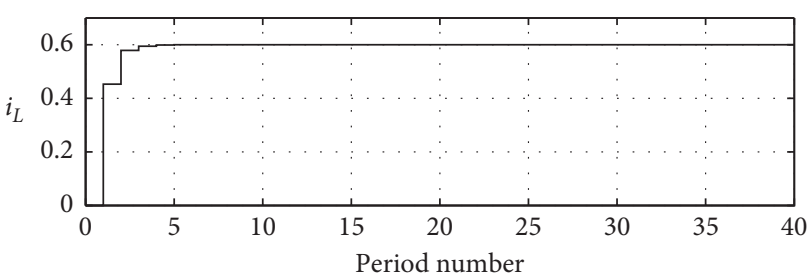

(a)

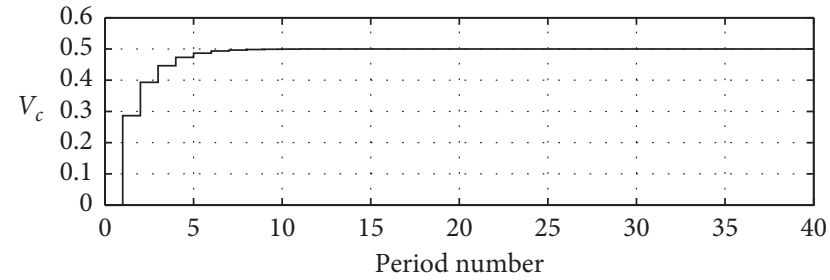

(b)

FIgURE 3: Time evolution of the current and the voltage.

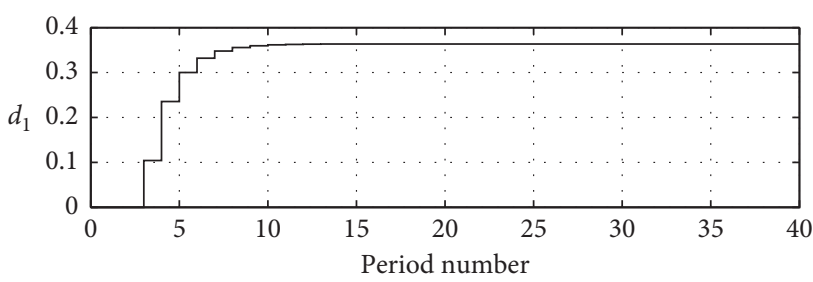

(a)

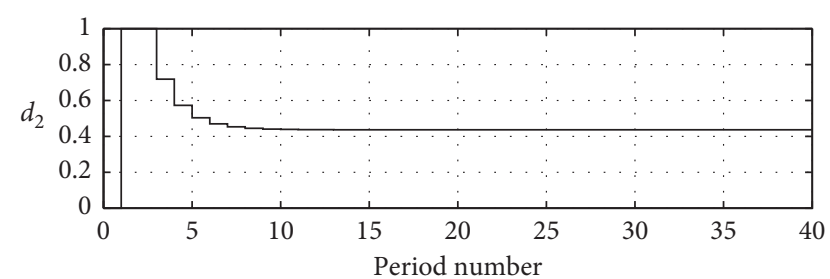

(b)

Figure 4: Time evolution of the duty cycles.

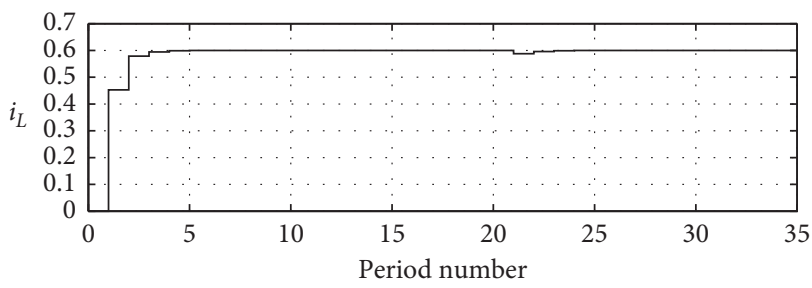

(a)

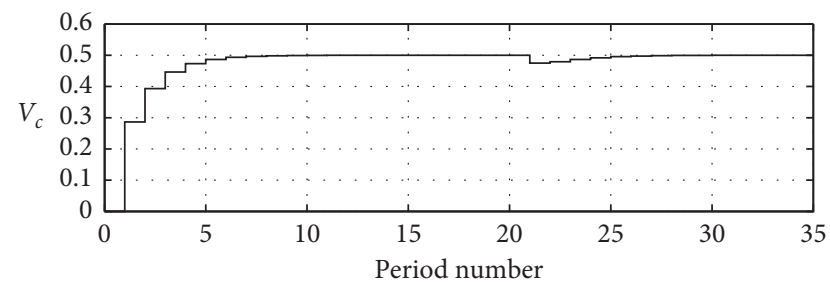

(b)

Figure 5: Time evolution of the current and the voltage. 

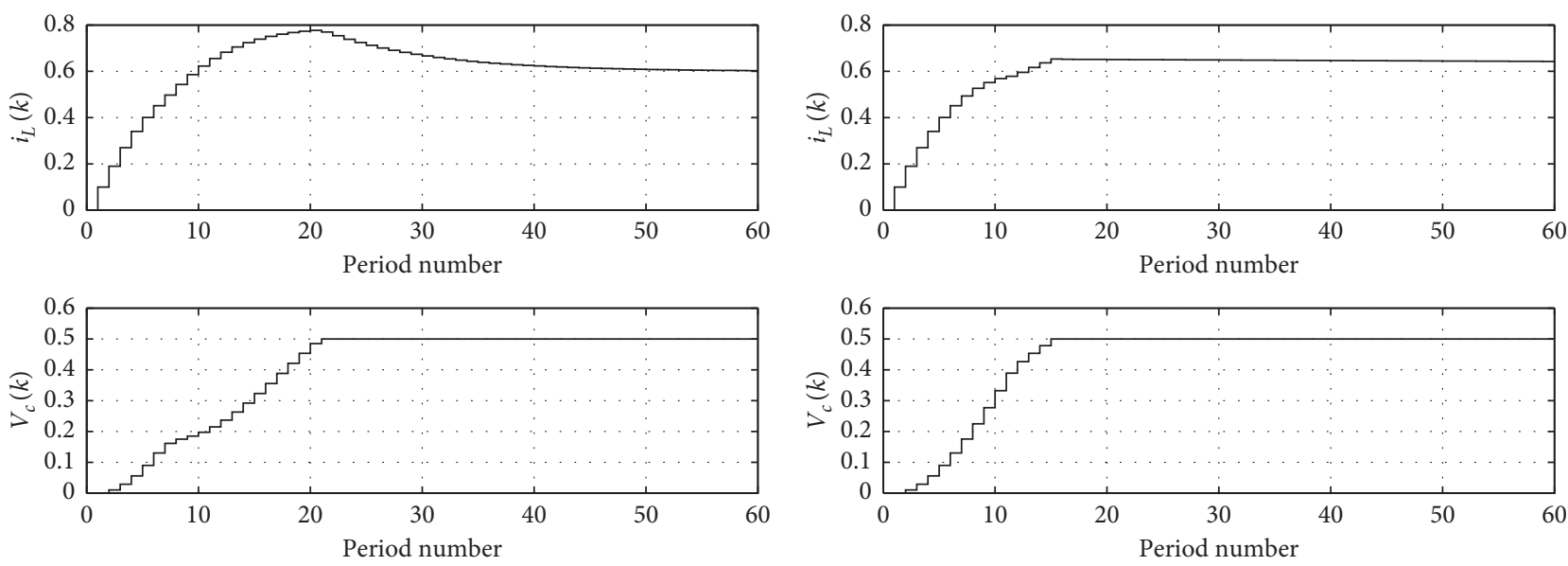

(a)

(b)

FIGURE 6: Simulation results of a PI controller: (a) for $k_{i}=8$; (b) for $k_{i}=0.4$.

$$
\begin{aligned}
& d_{1}(k)=k_{i}\left[i_{L}^{\prime}(k)-I_{r d}^{\prime}\right]+k_{v}\left[V_{c}^{\prime}(k)-V_{c d}^{\prime}\right]+u(k), \\
& d_{2}(k)=k_{i}\left[i_{L}^{\prime}(k)-I_{r d}^{\prime}\right]-k_{v}\left[V_{c}^{\prime}(k)-V_{c d}^{\prime}\right]+u(k),
\end{aligned}
$$

where

$$
u(k)=u(k-1)+\frac{k_{i}}{T_{i}}\left[i_{L}^{\prime}(k)-I_{r d}^{\prime}\right] .
$$

In [5], the authors calculate optimal parameters of a PI controller giving the faster response. The controller requires about 40 switching periods to drive the two-cell converter to the desired values and the current presents an important overshoot.

Figure 6 presents the behavior of the two-cell converter under the action of a PI controller with $k_{v}=(50 / 6)$ while $k_{i}$ is fixed first at $k_{i}=8$ and then at $k_{i}=0.4$. Obviously, desired values were reached without static errors with $k_{i}=8$ but it presents an overshoot on the current response. When $k_{i}$ is decreased, the overshoot is reduced but it makes a very slowly acting system. Thus, it is clear that the proposed controller achieves better performances than a PI controller. It is to be noted that for small values of the gain $k_{i}$, there is no static error on both current and voltage, but the systems become too slow. For example, in Figure 6(b), this error goes to zero after more than 400 switching periods.

\section{Conclusion}

In this paper, we have proposed a discrete type-2 fuzzy secondorder sliding mode controller for two-cell DC-DC converter which inherits the advantages of both sliding mode control and fuzzy systems. The second-order sliding mode control has been proposed as a robust method to control nonlinear and uncertain systems. Moreover, an online fuzzy adaptation scheme has been suggested to approximate unknown nonlinear functions. Simulation results on a DC-DC converter show the applicability and the effectiveness of the proposed controller.

\section{Data Availability}

The data used in this study are available within the article.

\section{Conflicts of Interest}

The authors declare that they have no conflicts of interest.

\section{References}

[1] Y. Lee, C. Chiu, and C. Shen, "Adaptive fuzzy terminal sliding mode control of DC-DC buck converters via PSoC," in Proceedings of the 2010 IEEE International Conference on Control Applications, Part of 2010 IEEE Multi-Conference on Systems and Control Yokohama, Yokohama, Japan, September 2010.

[2] T. Geyer, G. Papafotiou, and M. Morari, "On the optimal control of switch-mode DC-DC converters," Hybrid Systems: Computation and Control, vol. 2993, pp. 342-356, 2004.

[3] K. Koubaa, Analysis and Control of the Chaotic Behavior in a Multi-Cell DC/DC Buck Converter, Nova Science Publishers, New York, NY, USA, 2018.

[4] B. Robert and A. EL Aroudi, "Discrete time model of a multicell DC/DC converter: non linear approach," Mathematics and Computers in Simulation, vol. 71, no. 4-6, pp. 310-319, 2006.

[5] M. Feki, A. El Aroudi, and B. G. M. Robert, "Multi-cell DCDC converters: modelling, analysis and control," in Proceedings of the International Multi-Conference on Systems, Signals and Devices, Sousse, Tunisia, March 2011.

[6] A. Yang, L. Li, Z. Wang, and R. Guo, "Tracking control of a class of chaotic systems," Symmetry, vol. 11, no. 4, p. 568, 2019.

[7] C. Jiang, A. Zada, M. Tamer Senel, and T. Li, "Synchronization of bidirectional N-coupled fractional-order chaotic systems with ring connection based on antisymmetric structure," Advances in Difference Equations, vol. 2019, no. 1, pp. 1-16, 2019.

[8] C. Jiang, F. Zhang, and T. Li, "Synchronization and antisynchronization of $\mathrm{N}$-coupled fractional-order complex chaotic systems with ring connection," Mathematical Methods in the Applied Sciences, vol. 41, no. 7, pp. 2625-2638, 2018.

[9] M. He and J. Xu, "Nonlinear PID in digital controlled buck converters," in Proceedings of the APEC 07-Twenty-Second Annual IEEE Applied Power Electronics Conference and Exposition, pp. 1461-1465, Anaheim, CA, USA, March 2007.

[10] K. Furuta, "Sliding mode control of a discrete system," Systems \& Control Letters, vol. 14, no. 2, pp. 145-152, 1990. 
[11] W. Gao, Y. Wang, and A. Homaifa, "Discrete-time variable structure control systems," IEEE Transactions on Industrial Electronics, vol. 42, no. 2, pp. 117-122, 1995.

[12] H. Sira-Ramirez, "Non-linear discrete variable structure systems in quasi-sliding mode," International Journal of Control, vol. 54, no. 5, pp. 1171-1187, 1991.

[13] R. Fellag, M. Hamerlain, and S. Laghrouche, "Discrete first and second order sliding mode controllers for a pneumatic artificial muscles robot manipulator," in Proceedings of the 2015 4th International Conference on Electrical Engineering (ICEE), pp. 1-6, IEEE, Boumerdes, Algeria, December 2015.

[14] D. Khadija, L. Majda, and N. Ahmed Said, "Discrete second order sliding mode control for nonlinear multivariable systems," in Proceedings of the 2012 16th IEEE Mediterranean Electrotechnical Conference, pp. 387-390, IEEE, Yasmine Hammamet, Tunisia, March 2012.

[15] M. Mihoub, A. S. Nouri, and R. B. Abdennour, "Real-time application of discrete second order sliding mode control to a chemical reactor," Control Engineering Practice, vol. 17, no. 9, pp. 1089-1095, 2009.

[16] H. Medhaffar, M. Feki, and N. Derbel, "Stabilizing periodic orbits of chua's system using adaptive fuzzy sliding mode controller," International Journal of Intelligent Computing and Cybernetics, vol. 12, no. 1, pp. 102-126, 2019.

[17] R. Sakthivel, V. Nithya, P. Selvaraj, and O. M. Kwon, "Fuzzy sliding mode control design of Markovian jump systems with time-varying delay," Journal of the Franklin Institute, vol. 355, no. 14, pp. 6353-6370, 2018.

[18] N. N. Karnik, J. M. Mendel, and Q. Liang, "Type-2 fuzzy logic systems," IEEE Transactions on Fuzzy Systems, vol. 7, no. 6, pp. 643-658, 1999.

[19] J. M. Mendel, "Type-2 fuzzy sets as well as computing with words," IEEE Computational Intelligence Magazine, vol. 14, no. 1, pp. 82-95, 2019.

[20] N. N. Karnik and J. M. Mendel, "Centroid of a type-2 fuzzy set," Information Sciences, vol. 132, no. 1-4, pp. 195-220, 2001.

[21] H. Wu and J. M. Mendel, "Uncertainty bounds and their use in the design of interval type-2 fuzzy logic systems," IEEE Transactions on Fuzzy Systems, vol. 10, no. 5, pp. 622-639, 2002.

[22] J. M. Mendel, "Advances in type-2 fuzzy sets and systems," Information Sciences, vol. 177, no. 1, pp. 84-110, 2007.

[23] H. A. Hagras, "A hierarchical type-2 fuzzy logic control architecture for autonomous mobile robots," IEEE Transactions on Fuzzy Systems, vol. 12, no. 4, pp. 524-539, 2004.

[24] I. Atacak, "Design of a hybrid type-2 fuzzy logic/proportional integral controller for single-phase three-wire inverter system," Scientific Research and Essays, vol. 6, no. 23, pp. 5049-5064, 2011.

[25] K. Kaoubaâ, J. Pelaez-Restrepo, M. Feki, B. G. M. Robert, and A. E. Aroudi, "Improved static and dynamic performances of a two-cell DC-DC buck converter using a digital dynamic time-delayed control," International Journal of Circuit Theory and Applications, vol. 40, no. 4, pp. 395-407, 2012.

[26] K. Koubaa and M. Feki, "Quasi-periodicity, chaos and coexistence in the time delay controlled two-cell DC-DC buck converter," International Journal of Bifurcation and Chaos, vol. 24, no. 10, Article ID 1450124, 2014.

[27] R. Hamza, M. Feki, N. Derbel, B. G. M. Robert, and A. El Aroudi, "Controller design and analysis for a two-cell DC-DC converter in the presence of saturation," International Journal of Bifurcation and Chaos, vol. 21, no. 1, pp. 341-361, 2011.

[28] M. R. Amini, M. Shahbakhti, and S. Pan, "Adaptive discrete second-order sliding mode control with application to nonlinear automotive systems," Journal of Dynamic Systems, Measurement, and Control, vol. 140, no. 12, Article ID 121010, 2018.

[29] Y. Kali, M. Saad, K. Benjelloun, and A. Fatemi, "Discrete-time second order sliding mode with time delay control for uncertain robot manipulators," Robotics and Autonomous Systems, vol. 94, pp. 53-60, 2017.

[30] J. M. Mendel, Uncertain Rule-Based Fuzzy Logic Systems: Introduction and New Directions, Prentice-Hall, Upper Saddle River, NJ, USA, 2001.

[31] O. Castillo and P. Melin, Type-2 Fuzzy Logic: Theory and Applications, Springer-Verlag, Berlin, Germany, 2008.

[32] D. Wu and J. M. Mendel, "Designing practical interval type-2 fuzzy logic systems made simple," in Proceedings of the 2014 IEEE International Conference on Fuzzy Systems (FUZZIEEE), Beijing, China, July 2014.

[33] M. Nie and W. W. Tan, "Towards an efficient type-reduction method for interval type-2 fuzzy logic systems," in Proceedings of the 2008 IEEE International Conference on Fuzzy Systems (IEEE World Congress on Computational Intelligence), pp. 1425-1432, Hong Kong, China, June 2008.

[34] L. X. Wang, Adaptive Fuzzy Systems and Control, PrenticeHall, Englewood Cliffs, NJ, USA, 1994. 